$\xi=-1$

\title{
Analysis of Spatiotemporal Land Use and Land Cover Changes using Remote Sensing and GIS: A Review
}

\author{
Kabir Abdulkadir Gidado,2, Mohd Khairul Amri Kamarudin ${ }^{1,2 *}$, Nik Ahmad Firdaus ${ }^{2}$, Aliyu Muhammad \\ Nalado $^{2}$, Ahmad Shakir Mohd Saudi ${ }^{3}$, Muhammad Hafiz Md Saad ${ }^{2,4}$, Salisu Ibrahim ${ }^{5}$ \\ ${ }^{I}$ Faculty of Applied Social Sciences, Universiti Sultan Zainal Abidin, Gong Badak Campus, 21300 Kuala Nerus, Terengganu, Malaysia \\ ${ }^{2}$ East Coast Environmental Research Institute (ESERI), Universiti Sultan Zainal Abidin, Gong Badak Campus, 21300 Kuala Nerus, Ter- \\ engganu, Malaysia \\ ${ }^{3}$ Department of Environmental Health, Institute of Medical Science Technology Universiti Kuala Lumpur, Kajang, Selangor, Malaysia \\ ${ }^{4}$ AB Bakti Enterprise, Lot 27215 Kg. Gong Kuin 2, Jalan Tok Jembal, 21300 Kuala Nerus, Terengganu, Malaysia \\ ${ }^{5}$ Department of Geography, Faculty of Science, Kaduna State University, Kaduna State, Nigeria \\ *Corresponding authorE-mail: mkhairulamri@unisza.edu.my
}

\begin{abstract}
The land-use and land-cover (LULC) pattern of an area is an outcome of natural and socio-economic factors and their use spatially by man; this LULC varies from the forest, water body, agricultural land and so on. Remote Sensing (RS) and Geographical Information System (GIS) studies have predominantly focused on providing the technical knowledge of, where, and the type of LULC change that has occurred and its impacts on man and the environment. Knowledge about LULC changes is essential for understanding the relationships and interfaces between humans and the natural environment. The purpose of this article is to review the previous studies of the spatiotemporal LULC changes. However, thirty (30) articles were reviewed from 2011 to 2017. However, these articles studied the LULC, classification, changes and change detection analysis, using different methods and software of RS and G.I.S. The finding shows that these articles have overall accuracy assessment ranges from $75 \%$ to $95 \%$ validations. Also, supervised classification in Maximum Likelihood Algorithm method was mostly employed for the LULC classification. Moreover, these reviewed articles confirmed that LULC changes are imminent as a result of both natural and human factors which lead to increase and decrease of one LULC cover to another. Therefore proper monitoring of LULC changes when applied help the relevant government bodies, agencies and environmental managers utilise the environment to the fullest.
\end{abstract}

Keywords: Land Use; Land Cover; Environment; Remote sensing, G.I.S.

\section{Introduction}

Land-use and land-cover (LULC) change have become a vital factor in present procedures in managing natural resources and monitoring environmental changes $[1,2]$. Moreover, LULC changes are one of the major driving forces of changes in the Earth system and climate in particular, also an essential variable that effects on many parts of the human and physical conditions [3].

Furthermore, the world today focusses more on preserving the environment for the future generation, yet does not limit the current generation of how to use his immediate environment but the stress on cautions. These cautions gave birth to observations on changes happening to the environment, driving forces or factors bringing about the changes happening, prediction's or likelihood of future effect of the driving force and finally suggest a way to handle such effects.

Due to the lack of suitable land use development and the measures for sustainable development, widespread urban growth and loss of agricultural land have had severe environmental magnitudes. Also, the dyke-pond system, and environmentally protecting agricultureaquaculture knowledge, mainly established for utilising the coastal environment in the delta, has also experienced changes. These changes are likely to challenge the man-environment relationship.
Therefore there is the need for assessing the magnitude, outline, and type of land use and land cover changes, probably respond mainly to physical changes for future projections and developmental purposes $[4,5]$. However, the paper aims to review the classification of LULC changes using R S and G.I.S.

\section{Empirical Literature Review}

LULC data are records that documents to what extent a region is covered by wetlands, forests, agriculture, impervious surfaces, and other land and water forms. These water forms include open water or wetlands. Land use displays how people use landscape whether for conservation, development, or mixed uses [6, 7]. Land cover can be identified by analysing aerial and satellite imagery. However, land use cannot be identified from satellite imagery. Land cover maps give detail information that helps managers to understand the present landscape best. Furthermore, to see changes through time, land cover maps for numerous different years are needed. With this information, managers can assess past management verdicts as well as gain insight into the possible effects of their current decisions before they are implemented $[8,9]$.

According to [10], five types LULC pattern were classified barren land, agricultural lands, urban lands, quarries, and free water bodies, to detect the 25 years LULC change in the western Nile delta 
of Egypt. Supervised maximum likelihood classification (MLC) method was used in Erdas Imagine software. Landsat images 1984, 1999, 2005 and 2009 were used. The finding shows a significant change in barren land changing into agricultural land continuously from 1984 thru 2009.

Similarly, in [1] used the maximum likelihood algorithm (MLA) and Markov chain model (MCA) to study the LULC classification using ArcGIS and future prediction using Idiri respectively in Kathmandu city Nepal. Built-up, water body, forest area, open field and cultivated land classes classified. Results show built-up area significantly increased, and water body, forest area, open field and cultivated land decrease downward trend from 1976 to 2009. Furthermore, the Markov chain Analysis prediction for 2017 shows that in 2017 Urban area will increase to cover $72.24 \%$ of the total land in Kathmandu and cultivated land remains only $20.90 \%$. Waterbody and the open field will increase respectively by $0.59 \%, 0.19 \%$ whereas forest land decrease by $0.47 \%$.

Furthermore, in [10] used the Maximum likelihood classification (MLC), Change detection and spatial matrix analysis to analyse land cover change of fifty-year period (1954 to 2004) in Avellino Italy. The result shows 4 LULC classes, with urban land use increasing rapidly affecting the cultivated land mostly, while woodland and grassland cover decrease was at a lower rate.

Moreover, in [11] studied the LULC changes and structure in Dhaka metropolitan, Bangladesh in a period of 1975 to 2005. Maximum Likelihood Classification (MLC) and transition matrix method were used for LULC classification and rate/ pattern of LULC. The Result shows six classes in LULC of the water body, vegetation, bare soil, cultivated land built-up and wetland/lowland. Also, a significant increase in the built-up land, while cultivated land, vegetation and wetland decreased accordingly from 1975 to 2005.

Also, in [12] used Maximum Likelihood Classification and comparison method to study the LULC classification and change respectively from 1976 to 2003 in Tirupati, India. The results show 6 LULC classes, agricultural land, built-up, dense forest, plantation, water spread and other land, a significant increase in built-up area, plantation forests and other land, while a decrease on the part of the waterbody, dense forest and agricultural land was noticed. Moreover, in [13] studied the LULC change in Duzce plain Turkey. Supervised classification and the Corine land cover nomenclature methods used. The result shows 5 LULC classes as urban fabric, forest, heterogeneous agricultural land, inland wasteland and (Industrial, commercial, and transport) units with an accuracy assessment between $92.41 \%$ and $97.3 \%$ for LULC map 2010 and 1987 respectively. Also, a significant change in LULC was noticed with $11.2 \%$ increase in agricultural area and $335 \%$ decrease of forest land.

Furthermore, in [14] studied the spatiotemporal LULC change in Nukaru basin, Kenya. The hybrid classification and spatial reclassification methods were used. The result shows five LULC classes of open lands, built- up area, croplands, forests/shrublands, grasslands, and water bodies with an accurate assessment of $80 \%, 88 \%$, $89 \%$, and $95 \%$, years $2000,1973,2011$ and 1985 respectively. Also, a significant increase and a decrease of LULC were noticed between the years 1973, 1985, and 2000 within the classes.

Furthermore, in [15] studied the 18 years spatiotemporal LULC change at Tasik Chini Watershed, in Malaysia. In the years 1984 1990, 2000 and 2002. The study used GIS extrapolation analyses. The result shows 3 LULC classes in the year 1984 of water bodies, forests and oil palm plantations, additional three were noticed in the year 1990 which are agriculture, mining and rubber. By the year 2000 settlement was created, which translate to significant changes of LULC from the dominant forest which constitute of the significant cover in 1984 to create seven new LULC in the year 2002, with $75 \%$ changing to the new LULC.

Also, in [16] studied the 20 years spatiotemporal LULC in Hawalbagh block India, the supervised classification using, Maximum Likelihood Classification was used. The result shows 5 LULC classes namely agriculture, barren, built-up, vegetation, and water body, where $3.51 \%$ and $3.55 \%$ increase in vegetation and built-up areas, while a decrease of $5.46 \%, 1.52 \%$ and $0.08 \%$ of barren land agriculture, and water body respectively was noticed.

Furthermore, in [17] study the LULC change of watershed in Pakistan from 1992 to 2012 using the supervised classification of maximum likelihood algorithm in Erdas Imagine. The finding shows 5 LULC classes agriculture, bare soil/rocks, settlements, vegetation and water. Also, the water body and vegetation are decreasing in favour of settlements, agriculture and bare soil rapidly from $38.2 \%$ and $74.3 \%$ respectively.

Also, in [18] study, both unsupervised (ISODATA) and supervised (MLA) methods were used for LULC classification. Change detection and Markov change analysis methods used to measure the LULC changes and generate future LULC map respectively in Mansoura and Talkha of Egypt from 1985 to 2010. The finding shows four LULC classes viz agriculture, barren land, built-up area and water body. Also, a significant change was noticed in agricultural land and built-up area to tune of $33 \%$ decrease and $30 \%$ increase respectively, while barren land and water bodies changes were minimal.

Similarly, in [19] studied the LULC classification of Sawantwadi taluka, in India. The hybrid, parametric (MLA and ISODATA), and nonparametric (DT) methods were used. The finding shows the classified LULC of the forest, water, built-up, agriculture, plantation, fallow land, open and dense shrubland, stone quarry, and grassland with an accuracy assessment of 93\% and koppa of 0.92 .

Also, in [20] measured the LULC change in Seramban. In the study, Natural Breaks (Jenks) and Normalized Difference Vegetation Index (NDVI) methods were used for classification and difference from 1990 to 2000. The result shows four classes of LULC viz barren land, built-up area, vegetation and water body. A $13 \%$ decrease in vegetation cover was noticed while other land use/ land cover increase by $3.7 \%$ accordingly with an accuracy assessment of $87 \%$ and $88 \%$ respectively.

Likewise, in [21] studied twenty-five years the spatiotemporal urban growth of Kuala Lumpur, using the Maximum Likelihood Classification (MLC) method for years 1989, 2001 and 2014. The result shows 4 LULC classes agriculture, urban/built-up, forest, and water body. Also, a rapid increase of the built-up areas and agricultural land was noticed while other land covers decrease very significantly.

Also, in [22] used NDVI method to study the LULC change of Sambas watershed, in Malaysia for the years 1990, 2002 and 2013. The results show 5 LULC classes viz barren land, forest, grassland, shrub and water body. A significant decrease in the forest cover was noticed, while barren land and grassland was increasing accordingly throughout the period.

Also, in [23] studied the ten years LULC changes of Aluva taluk, in India from 2000 to 2010. Supervised classification (MLA) and Change Detection Analysis were used for LULC classification and mapping. The result shows 8 LULC classes viz Agriculture, Built up, Cropland, Fallow land, Forest deciduous, Forest evergreen, Plantation, and Waterbody. A significant change in some LULC was noticed.

Furthermore, in [24] used change detection matrix in the study of LULC change of Kolong River basin of India in the years 1967-68 and 2014. The finding shows six LULC classes viz agricultural land, built- up, forest, open space, shrub and wetland. A significant change in two primary land use, agricultural land and built-up area with the former decreasing in the year 1967-68 and the later increasing much in the year 2014 respectively.

Similarly, in [25] used supervised Maximum likelihood classification (MCL), and multi-layer Perceptron-Markov chain analysis (MLP-MCA) to monitor the LULC changes as well predict future LULC changes in Patna India. The result shows seven classes of LULC viz agriculture, built-up, Fallow land, Riverbed, Shrubs, Vegetation, Water bodies. A slight change in the LULC was noticed across the classes, in a decrease and increases pattern. Also, the prediction shows significant changes in the built-up area.

Moreover, in [26] studied 31 years LULC change in Beressa Watershed Ethiopia from 1984 to 2015. Unsupervised ISODATA 
using Erdas imagine and Change Detection methods were used in LULC classification and change magnitude respectively. The finding shows six classes of LULC viz barren land, farmland, forest/plantation, grazing land, settlement, and water body. A continuous increase in settlement and farmland, while grazing land and barren were decreasing over the three decades.

Furthermore, in [27] studied LULC changes in Udhaim river basin in Iraq using Landsat TM image for 2006 and OLI 2015. Spectral indices (NDVI, NDBI, NDWI, NDBaI, and CI) methods were used to study for LULC classification and changes. The finding shows 5 LULC according to each index viz bare land, built-up, soil crust, vegetation and water body. Also, significant changes were noticed in the LULC with $3 \%$ increase soil crust, and $2.43 \%$, $0.6 \%, 0.55 \%$ and $0.22 \%$ decrease in vegetation cover, built-up area, bare land and water body respectively.

Likewise, in [28] study the LULC of Kan basin from 2000 to 2016. Supervised classification of (MLA) method and Change Detection Analysis were used. The finding shows 5 LULC classes viz bareland, built up, garden, pasture, and water body. Also, found a slight increase of $0.3 \%$ and $0.2 \%$ of pasture and build-up areas respectively, while bare land, garden, and water body decrease slightly over sixteen years by $0.4 \%$ and $0.01 \%$ respectively with an accuracy assessment of $86 \%$ and $89 \%$ for years 2000 and 2016 respectively.

Moreover, in [29] study the LULC change of hotspot area in Pune region using Landsat images for 1972, 1992, and 2012. Change Detection and Statistical Cluster Analysis method for LULC change were used. The result shows 10 LULC classes viz cropland, fallow land, forests, industrial, rivers, rural, tree clads and Wastelands with an accuracy assessment range from $77 \%$ to $97 \%$. A significant change was noticed, an increase in fallow land, industrial, and built-up areas around the hotspot region.

Also, in [30] studied ten years LULC change and transformations in Kanyakumari coast India. The study used supervised classification of (MLA) and Change Detection. The finding shows 8 LULC classes viz barren land, built-up, beach face, cultivable lands, fallow land, mining, vegetation, and water body. A significant change in the coastal LULC of Kanyakumari was noticed, some LULC changing to another over the ten-year period with accuracy assessment of $81.16 \%$ and $77.52 \%$ for image 2000 and 2011 respectively.

Also, in [31] study the LULC change in Tanguar Haor, Bangladesh. The study used supervised classification in (MLA) for classification and CVA, NDVI and NDWI analysis were used to for change detection analysis. The result shows 4 LULC classes viz deep water, vegetation, shallow water, and settlement. A significant change in the LULC with about $40 \%$ of the total area transformation, i.e. changing from one LULC to another.

Furthermore, in [32] used Google Earth and GIS Operation to study the LULC changes in Muar sub-district in Malaysia from the year 2010 to 2015 . The results show 6 LULC classes viz agriculture, barren land, built-up, forest, open/ reaction space and roads. Also shows a significant change in the overall LULC across the district, i.e. some land covers a been converted into another form.

Also, in [33] studied the spatial-temporal LULC change in Astrakhan city, Russia, from the year 2000 to 2015. Supervised (MLA) and change detection analysis was used to classify the LULC and monitor the LULC change within the period. The result shows 5 LULC classes viz agriculture, bare-land, settlements, vegetation and water body. It further shows large vegetation dilapidation and water logging in different parts of the. Astrakhan city

Also, in [34] used supervised (MLA) classification and Stochastic Markov (St Markov) method, to study the LULC change and predict future urban land use in Jodhpur City in India from 1990 to 2000. The finding shows 5 LULC classes viz built-up, mining area, other land, vegetation, and water body. It further shows the rates of changes from one LULC to the other.

Furthermore, in [35] studied the LULC change Khan-Kali watershed and Anas River from Gujarat, India between the year 2001 and 2011. Supervised classification (MLA) and NDVI and NDWI methods were used for LULC classification and change detection respectively. The results 7 LULC classes viz agriculture, barren land, built-up, forest, riverine sand, shrubland, and water body with an overall accuracy assessment of $91.8 \%$ and $95.5 \%$ for years 2001 and 2011 respectively. Also, a significant increase in the water body and shrub land while a decrease in the forest, barren land and riverine LULC.

Moreover, in [36] studied LULC classification in Okara, Pakistan. The supervised classification of MLA and Synthetic Aperture Radar (SAR) methods were used. The finding shows four classes of LULC, barren land, built-up, water body and vegetation, with an overall accuracy of $80 \%$ and 0.69 Kappa coefficients.

Also, in [37] in their study, Google Earth Engine (GEE) and Normalized Difference Vegetation Index (NDVI) method were used for LULC classification and detect major LULC changes from 1985 to 2014 in Beijing respectively. The finding shows seven classes of LULC viz cropland, grassland, forest, shrub, water body, built-up, and barren land, with an overall accuracy of $86.61 \%$. However, GEE proved to be a quick and efficient tool for LULC mapping and map classification in the study.

\section{Conclusion}

The main objective of this article is to review the previous studies of the spatiotemporal LULC changes using RS and GIS. It was observed in the review; different GIS software is used for different methods by many researchers such as supervised MLA, MLC, CD, GEE, SAR, NDVI, MCA, DT, the Hybrid, Transition matrix, Corine land cover nomenclature, and the unsupervised classification. Supervised classification using (MLA) is the predominant method used for LULC classification, while other methods were either used to detect the LULC changes or future LULC prediction. Also, the classified classes are a mostly built-up area or urban areas, agriculture, water body, barren land, forest, shrubland, and other land. Furthermore, RS and GIS serve as best and efficient tools for general and more detailed LULC change analysis. In conclusion, the study of LULC changes provides detail on the type of changes and magnitude in a spatial location, his help the government, and general land user a guide for proper environmental monitoring and management.

\section{Acknowledgement}

The authors acknowledge the financial assistance from SRGS Grant: Pembangunan Pemodelan Luahan Persekitaran Ekohidrologi Di Tasik Kenyir, Hulu Terengganu, Terengganu. Grant no: (UniSZA/2017/SRGS/17) - R0019-R017 and RAGS 2015 Siasatan Penghasilan Sedimen. Grant no: RAGS/ 1/2015 /WAB05/ UNISZA/02/1, East Coast Environmental Research Institute, FSSG, Universiti Sultan Zainal Abidin (UNISZA) for giving us permission to utilize the research facilities, advice, guidance, and support for this study.

\section{References}

[1] Rimal, B. (2011). Application of remote sensing and GIS, land use / land cover change in Kathmandu Metropolitan City, Nepal Journal of Theoretical and Applied Information Technology, 23(2), 80-86.

[2] Kamarudin, M. K. A., Gidado, K. A., Toriman, M. E., Juahir, H., Umar, R., Abd Wahab, N., Ibrahim, S., Awang, S., \& Maulud, K. N A. (2018). Classification of land use/land cover changes using GIS and remote sensing technique in Lake Kenyir Basin, Terengganu, Malaysia. International Journal of Engineering and Technology, 7(3.14 Special Issue 14), 12-15

[3] Verburg, P. H., Neumann, K., \& Nol, L. (2011). Challenges in using land use and land cover data for global change studies. Global Change Biology, 17(2), 974-989.

[4] Kamarudin, M. K. A., Wahab, N. A., Juahir, H., Wan, N. M. F. N. Gasim, M. B., Toriman, M. E., Ata, F. M., Ghazali, A., Anuar, A., Abdullah, H., Hussain, N. I., Azmee, S. H., Saad, M. H. M., Saupi, 
M., Islam, M. S., \& Elfithri, R. (2018). The potential impacts of anthropogenic and climate changes factors on surface water ecosystem deterioration at Kenyir Lake, Malaysia. International Journal of Engineering and Technology, 7(3.14 Special Issue 14), 67-74.

[5] Weng, Q. (2002). Land use change analysis in the Zhujiang Delta of China using satellite remote sensing, GIS and stochastic modelling. Journal of Environmental Management, 64(3), 273-284.

[6] dos Santos, J. C. N., de Andrade, E. M., Medeiros, P. H. A., Guerreiro, M. J. S., \& Palácio, H. A. Q. (2017). Land use impact on soil erosion at different scales in the Brazilian semi-arid. Revista Ciencia Agronomica, 48(2), 251-260.

[7] Kamarudin, M. K. A., Abd. Wahab, N. A., Mamat, A. F., Juahir, H., Toriman, M .E., Wan, N. F. N., Ata, F. M., Ghazali, A., Anuar, A., \& Saad, M. H. M. (2018). Evaluation of annual sediment load production in Kenyir Lake reservoir, Malaysia. International Journal of Engineering and Technology, 7(3.14 Special Issue 14), pp. 55-60.

[8] Prestele, R., Arneth, A., Bondeau, A., De Noblet-Ducoudré, N., Pugh, T. A. M., Sitch, S., Stehfest. E., \& Verburg, P. H. (2017). Current challenges of implementing anthropogenic land-use and land-cover change in models contributing to climate change assessments. Earth System Dynamics, 8(2), 369-386

[9] Abd El-Kawy, O. R., Rød, J. K., Ismail, H. A., \& Suliman, A. S. (2011). Land use and land cover change detection in the western Nile delta of Egypt using remote sensing data. Applied Geography, 31(2), 483-494.

[10] Fichera, C. R., Modica, G., \& Pollino, M. (2012). Land cover classification and change-detection analysis using multi-temporal remote sensed imagery and landscape metrics. European Journal of Remote Sensing, 45(1), 1-18.

[11] Dewan, A. M., Yamaguchi, Y., \& Rahman, M. Z. (2012) Dynamics of land use/cover changes and the analysis of landscape fragmentation in Dhaka Metropolitan, Bangladesh. GeoJournal, 77(3), 315-330.

[12] Mallupattu, P. K., Reddy, J., \& Reddy, S. (2013). Analysis of land use / land cover changes using remote sensing data and GIS at an Urban Area, Tirupati, India. Scientific World Journal, 2013, 1-7.

[13] Ikiel, C., Ustaoglu, B., Dutucu, A. A., \& Kilic, D. E. (2013). Remote sensing and GIS-based integrated analysis of land cover change in Duzce plain and its surroundings (north western Turkey). Environmental Monitoring and Assessment, 185(2), 1699-1709.

[14] Were, K. O., Dick, T. B., \& Singh, B. R. (2013). Remotely sensing the spatial and temporal land cover changes in Eastern Mau forest reserve and Lake Nakuru drainage basin, Kenya. Applied Geography, 41, 75-86.

[15] Mir, S. I., Muhammad Barzani, G., Mohd Ekhwan, T., Sahibin, A., \& Zularisam, A. W. (2012). Application of GIS for detecting changes of land use and land cover in Tasik Chini watershed, Pahang, Malaysia. International Journal of Civil Engineering and Geo-Environmental, 3, 13-21

[16] Rawat, J. S. e, \& Kumar, M. (2015). Monitoring land use/cover change using remote sensing and GIS techniques: A case study of Hawalbagh block, district Almora, Uttarakhand, India. The Egyptian Journal of Remote Sensing and Space Science, 18(1), 7784.

[17] Butt, A., Shabbir, R., Ahmad, S. S., \& Aziz, N. (2015). Land use change mapping and analysis using Remote Sensing and GIS: A case study of Simly watershed, Islamabad, Pakistan. The Egyptian Journal of Remote Sensing and Space Science, 18(2), 251-259.

[18] Hegazy, I. R., \& Kaloop, M. R. (2015). Monitoring urban growth and land use change detection with GIS and remote sensing techniques in Daqahlia governorate Egypt. International Journal of Sustainable Built Environment, 4(1), 117-124.

[19] Kantakumar, L. N., \& Neelamsetti, P. (2015). Multi-temporal land use classification using hybrid approach. Egyptian Journal of Remote Sensing and Space Science, 18(2), 289-295.

[20] Aburas, M. M., Abdullah, S. H., Ramli, M. F., \& Ash'aari, Z. H. (2015). Measuring land cover change in Seremban, Malaysia using NDVI index. Procedia Environmental Sciences, 30, 238-243.

[21] Boori, M. S., Netzband, M., Choudhary, K., \& Voženílek, V. (2015). Monitoring and modeling of urban sprawl through remote sensing and GIS in Kuala Lumpur, Malaysia. Ecological Processes, $4(1), 1-10$

[22] Kundu, S. N., \& Bei, T. J. (2016). Multi-temporal land cover change analysis of the Sambas watershed, West Kalimantan, East Malaysia: Implications for tropical erosion. Proceedings of the International Geoscience and Remote Sensing Symposium, pp. 5193-5196.
[23] George, J., Baby, L., Arickal, A. P., Vattoly, J. D., Use, L., \& Cover, L. (2016). Land use / land cover mapping with change detection analysis of Aluva Taluk using remote sensing and GIS. International Journal of Science, Engineering and Technology, 4(2), 383-389.

[24] Bora, M., \& Goswami, D. C. (2016). Spatio-temporal landuse / landcover (LULC) change analysis of Kolong River basin, Assam, India using Geospatial technologies. International Journal of Geomatics and Geosciences, 6(3), 1676-1684.

[25] Mishra, V. N., \& Rai, P. K. (2016). A remote sensing aided multilayer perceptron-Markov chain analysis for land use and land cover change prediction in Patna district (Bihar), India. Arabian Journal of Geosciences, 9(4), 1-18.

[26] Meshesha, T. W., Tripathi, S. K., \& Khare, D. (2016). Analyses of land use and land cover change dynamics using GIS and remote sensing during 1984 and 2015 in the Beressa Watershed Northern Central Highland of Ethiopia. Modeling Earth Systems and Environment, 2(4), 1-12.

[27] Mail, A. A. S. M. (2017). Desertification detected in the Udhaim River Basin, Iraq based on spectral indices derived from remote sensing images. Miscellanea Geographica, 21(3), 124-131.

[28] Halimi, M., Sedighifar, Z., \& Mohammadi, C. (2017). Analyzing spatiotemporal land use/cover dynamic using remote sensing imagery and GIS techniques case: Kan basin of Iran. GeoJournal, 83(5), 1067-1077.

[29] Ganguly, K., Kumar, R., Mruthyunjaya Reddy, K., Jagadeeswara Rao, P., Raj Saxena, M., \& Ravi Shankar, G. (2017). Optimization of spatial statistical approaches to identify land use/land cover change hot spots of Pune region of Maharashtra using remote sensing and GIS techniques. Geocarto International, 32(7), 777796.

[30] Kaliraj, S., Chandrasekar, N., Ramachandran, K. K., Srinivas, Y., \& Saravanan, S. (2017). Coastal landuse and land cover change and transformations of Kanyakumari coast, India using remote sensing and GIS. Egyptian Journal of Remote Sensing and Space Science, 20(2), 169-185.

[31] Haque, M. I., \& Basak, R. (2017). Land cover change detection using GIS and remote sensing techniques: A spatio-temporal study on Tanguar Haor, Sunamganj, Bangladesh. Egyptian Journal of Remote Sensing and Space Science, 20(2), 251-263.

[32] Yeo, L. B., Said, I., Saito, K., \& Fauzi, A. M. (2017). Mapping land use/ cover changes and urbanization at subdistricts of Muar, Malaysia. Chemical Engineering Transactions, 56, 289-294.

[33] Choudhary, K., Boori, M. S., \& Kupriyanov, A. (2017). Landscape analysis through remote sensing and GIS techniques: A case study of Astrakhan, Russia. Proceedings of the SPIE - International Society for Optical Engineering, 10225, 1-6.

[34] Borana, S. L., \& Yadav, S. K. (2017). Markov chain modelling of land cover changes in Jodhpur City. International Journal of Engineering Development and Research, 5(4), 2-7.

[35] Thakkar, A. K., Desai, V. R., Patel, A., \& Potdar, M. B. (2017). Impact assessment of watershed management programmes on land use/land cover dynamics using remote sensing and GIS. Remote Sensing Applications: Society and Environment, 5, 1-5.

[36] Khalil, R. Z., \& Saad-ul-Haque. (2017). InSAR coherence-based land cover classification of Okara, Pakistan. Egyptian Journal of Remote Sensing and Space Science, 21, S23-28.

[37] Huang, H., Chen, Y., Clinton, N., Wang, J., Wang, X., Liu, C., Gong, P., Yang, J., Bai, Y., Zheng, Y., \& Zhu, Z. (2017). Mapping major land cover dynamics in Beijing using all Landsat images in Google Earth Engine. Remote Sensing of Environment, 202, 166176. 